\title{
Anatomical consideration of the number and form of the papillary muscle in the left ventricle
}

Faculty of Medicine, University "Ovidius" of Constanta

\begin{abstract}
Our results were obtained by dissection of 56 cords, wich presented at the papillary muscle of the left ventricle, 106 muscular bodies and from those, 58 muscular bodies were for the anterior papillary muscle and 48 for the posterior papillary muscle. Anterior papillary muscle was studied on 32 cords, and the posterior papllary muscle on 24 cases. Of the 106 papillary muscles we analized, unique papillary muscle was incountered in 16 cases, 10 being at the anterior papillary muscle and 6 cases at the posterior papillary muscle.

The papillary muscle formed of two muscular bodies (double) presented a number of 64 muscular bodies, 36 being at the anterior papillary and 28 at the posterior papillary. In cases of triple papillary muscle, from 18 muscular bodies, 12 were from the anterior papillary and 6 were from posterior papillary. In the two cases of quadruple papillary muscle the 8 muscular bodies belonged to the posterior papillary muscle.

Amoung the total muscular bodies, most frequently they had a conical shape, aspect found in 67 cases, 33 cases being seen in the anterior papillary muscle and 34 in the posterior papillary. In 20 cases the muscular bodies were cylindrical, 18 cases were found in the anterior papillary and 2 in the posterior papillary muscle. In 10 cases the muscular bodies were arcuated, 4 cases being to anterior papillary and 6 cases to the posterior papillary muscle. In 8 cases the bodies were fusiform, 4 cases being to the anterior papillary and 4 to the posterior papillary
\end{abstract}

Marius Toba

Faculty of Medicine, University “Ovidius" of Constanta University Street, No. 1, Campus B

Constanta, Romania

email: rux.gheorghitescu@gmail.com

phone: +40736629594 muscle. In one case to an unique posterior papillary muscle we found a particullar form of the muscular body, wich we called ,the torch” or the „beacon” that have the muscular body thinner at the lower half and the size increasing in width, reaching a maximum width at its upper extremity, from where are detaching four extra muscles that gave birth to beams of valvular chordage. In case of papillary muscles with two muscular bodies, they can sometimes be linked by a muscular bridge, transverse or oblique, making characteristical features. Thus, in 6 cases, the muscular bridges realized the H" letter appearance, 4 cases being at the anterior papillary muscle and 2 at the posterior papillary. In 4 cases only at the anterior papillary the bridges formed „N" letter aspect, 2 cases were at the anterior papilllary and 2 in the posterior papillary muscle. Also in 4 cases, the presence of the bridges acheve the appearance of reversed „N" letter, 2 cases were in the anterior papillary and 2 in the postertior papillary.

Keywords: anatomical forms papillary muscles left ventricle

\section{Introduction}

The inner surface of the ventricles, contrary to their outter surface wich is smooth, has a system of protrusions and muscular extensions, wich are crossed in all directions, giving the ventricular wall a cellular and cross-linked aspect [1].

These protrusions are called fleshy columns [1] or fleshy trabeculaes [2].

After their disposal they are classified into three orders, the first order being called papillary 
muscles [2] or pillars $[1,3,4,5]$, attaching themselves to the ventricular wall by their lower end (base). The other end is free and gives rise to the cordage tendons that will insert to the appropriate cusps of the atrioventricular valve. The left ventricle presents two papillary muscles, anterior and posterior $[1,3,4,5]$. Those two papillary muscles are stronger than those of the right ventricle $[6,7]$, considering the higher labor they perform. They can arise with many roots $[3,6,8,9]$ or they can have mamillary ends $[4,10]$, most commonly the posterior one $[11,12]$. Sometimes there may be more than two papillary muscles, one of them showing more than one muscular body $[9,10$, 13].

Therefore, some authors believe that there is an anterior papillary group and a posterior one, the muscular body of the papillary muscles are more or less reunited by the base and branched at the top $[10$, 14]. The shape of the papillary muscles of the left ventricle is described very differently by the authors. Following [3], anterior papillary is irregular, conical or cylindrical, and the posterior one has the front face excavated, whose concavity adapts to the convex posterior face af the anterior papillary. To [4] anterior papillary the tip is conical, more or less rounded, and the posterior papillary muscle has the form of a gutter, whose concavity during systola match perfectly to the convexity of the anterior papillary. [15] states that in the left ventricle the majority papillary muscles have conical form. [10] finds papillary muscles of conical shape with one end rounded.

After $[8,13]$ unique papillary muscle may be conical, mammillated, flattiped (beveled), stepped, wavy, curved, angled or saucerized, or may be groove shaped. When single describes a type of papillary muscle showing from the muscular body side an extension, called ", glove finger".

When there are two muscular bodies, they can be parallel, or they can be linked at different levels to form different configurations: $\mathrm{V}, \mathrm{Y}$, or $\mathrm{H}$. When there are three muscular bodies, they can be parallel, or linked to each other, or they can form arcuate arrangements. with the third muscular body that is separate.Sometimes, two muscular bodies are interconnected to each other or they form with the third one, wich is sepparated, an arrangement. When there are four or five muscular bodies they can be parallel or linked to each other [13]. Gunnal [ 8 ] identifies four different forms of papillary muscles: conical, wide tip (flat), pyramidal or fan-shaped. Also describes various models of papillary muscles: separate base and flat tip, single base and peak divided, „small projections” of papillary muscles, long papillary muscles, ,puncture" papilllary muscles and papillary muscles with the base attached to a large muscule bridge. Berdajs [17] describes three groups of papillary muscles in the left ventricle. From group I the base and the peak were undivided. In group II there are two types of muscular bodies, describing two subgroups: in subgroup II/0the base of papillary muscle was undivided and in subgroup II/B the base was consisted of two sepparate parts. In group III the papillary muscle have three bodies describing three subgroups: subgroup III/A base was undivided, subgroup III/B the base was consisted of two parts and III/C of three parts.

\section{Material and methods:}

Our results were obtainded by analysis of 56 cords, wich presented 106 muscular bodies at the papillary muscules of the left ventricle, including 58 muscle bodies for anterior papillary muscles and 48 muscular bodies for the posterior papillary muscles.

The study was performed by dissecting both fresh cords and formalined cords, aiming: the number of the muscular bodies of each papillary muscle, the form of the muscular body, the way implants the base of the muscular body on the ventricular wall, and how the valvular extremity of it, ends.

\section{Results}

The 106 of left ventricle papillary muscles 
were from a number of 56 cords, the anterior papillary muscle was pursued on 32 cords $(57,14 \%$ of cases) and the posterior paillary on 24 cases $(42,86 \%$ of cases). The unique papillary muscle was found on 16 cord ( $28,57 \%$ of cases), the anterior one being single in 10 cases $(17,86 \%$ of total cords and $31,25 \%$ of the anterior papillary muscle), andthe posterior in 6 cases $(10,71 \%$ of all cords and $25 \%$ of cases of posterior papillary muscle). Left double papillary muscle we found in 32 cords $(57,14 \%$ of cases $)$ the anterior one being double in 18 cords ( $56,25 \%$ of all cords and $56,25 \%$ of cases of the anterior papilary), the posterior one in 14 cases $(25 \%$ of all cords and $58,33 \%$ of the posterior papillary muscle).

Triple left papillary muscle we found in 6 cords $(10,71 \%$ of cases $)$, the anterior one being triple in 4 cords $(7,14 \%$ of all cords and $12,5 \%$ of cases of anterior papillary muscles) and the posterior one in 2 cases $(3,57 \%$ of all cords and $8,33 \%$ of posterior papillary muscles). The quadruple left papillary muscle we found in two cords $(3,57 \%$ of all cases) aspect found only at the posterior papillary ( $8,33 \%$ of posterior papillary muscle)

From 106 muscular bodies of the left ventricle the papillary muscles that we analyzed on 56 cords, we found unique papillary muscle in 16 cases $(15,09 \%$ of cases), 10 cases being at theanteriorpapillary muscle $(17,24 \%$ of anterior papillary muscle) and 6 cases at the posterior papillary muscle ( $12,5 \%$ of the posterior papillary muscle).

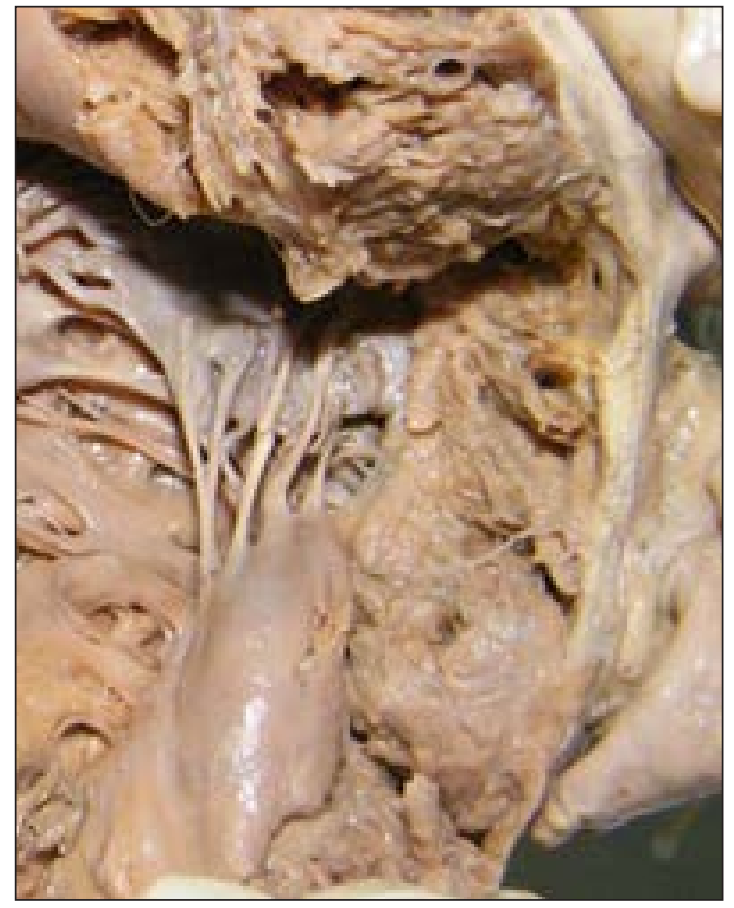

Figure 1. Unique anterior papillary muscle, conical shape

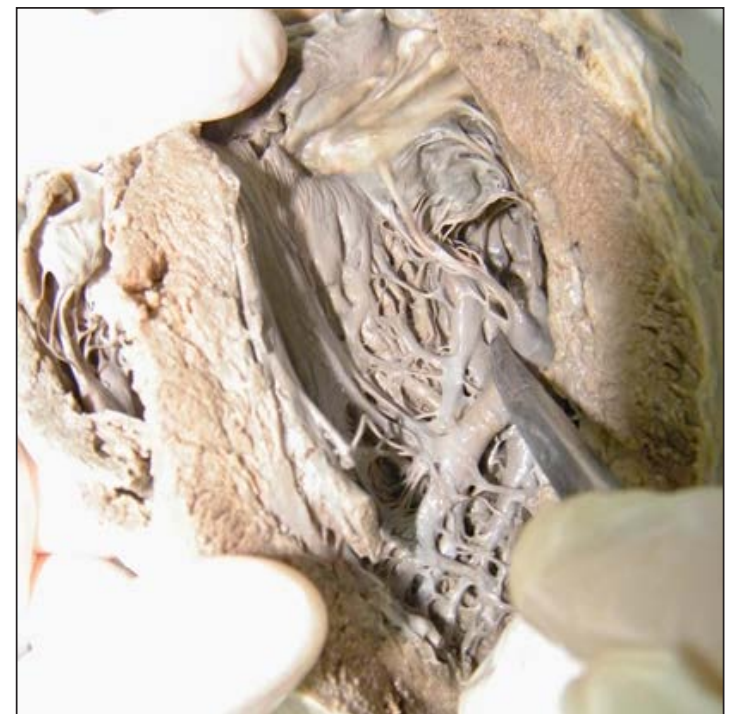

Figure 2. Anterior papillary muscle, with two conical muscular bodies, dispose one anterior to the other

The 2 cases of papillary muscle with two muscular bodies (double) present a total of 64 muscule bodies $(60,38 \%$ of muscle bodies), 36 being at the anterior papillary muscle $(62,07 \%$ of the anterior muscular bodies ) and 28 bodies at the 
posterior papillary muscles $(62,07 \%$ of posterior papillary muscule bodies). In case of triple papillary muscules from 18 muscule bodies $(16,98 \%$ of all muscular bodies), 12 bodies were at the anterior papillary $(20,69 \%$ of all anterior muscular bodies) and 6 muscular bodies were at the posterior papillary muscule $(12,5 \%$ of all posterior muscular bodies). The 2 cases with quadruple papillary presented 8 muscular bodies $(7,55 \%$ of all muscular bodies), all of them being found at the posterior papillary $(16,67 \%$ of all posterior bodies). Of the total of muscular bodies, most frequently they had conical shape, aspect found in 67 cases $(63,21 \%$ of total muscular bodies $), 33$ casesbeing found at the anterior papillary $(56,90 \%$ of all anterior muscule bodies) and 34 cases at the posterior papillary $(70,83 \%$ of all posterior muscule bodies).

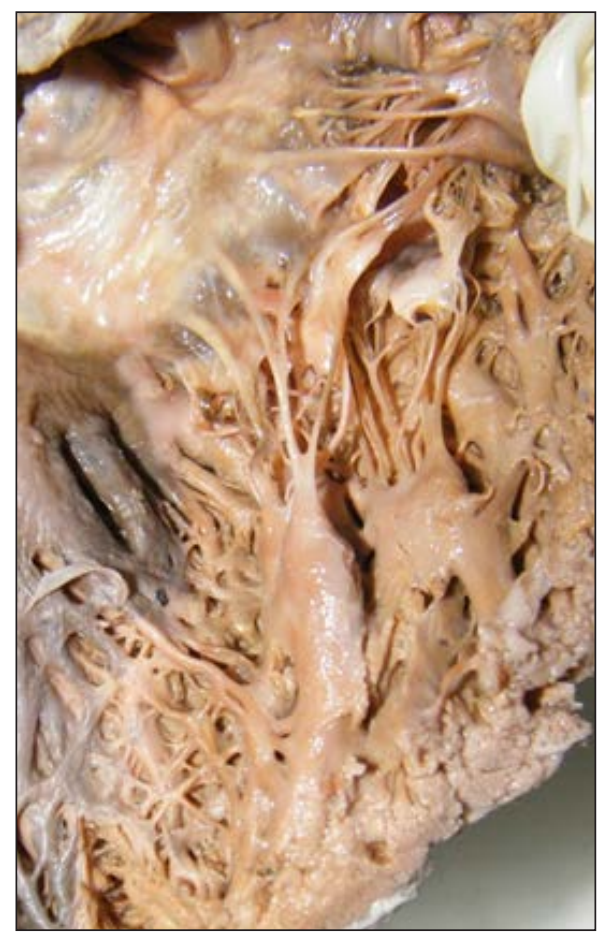

Figure 3. The anterior papillary muscle with two muscular bodies, with almost same sizes, both in archway, one left and other right

On 20 cases $(18,87 \%$ of cases, the muscular bodies were cylindrical, 18 cases being found at the anterior papillary muscule $(31,03 \%$ of all anterior muscular bodies); in case of the posterior papillary muscules found only two cases $(4,17 \%$ of all posterior muscular bodies). In 10 cases $(9,43 \%$ of all 106 cases) the muscular bodies were arcuated, 4 cases being at the anterior papillary muscle $(6,90 \%$ of all anterior muscular bodies) and 6 cases at the posterior papillary muscule $(12,5 \%$ of all posterior muscular bodies). In 8 cases $(7,55 \%$ of cases), the muscular bodies were fusuform, 4 cases at the anterior papillary muscule $(6,90 \%$ of all anterior muscular bodies) and 4 at the posterior papillary $(8,33 \%$ of posterior muscular bodies). In only one case $(0,94 \%$ of cases $)$ at an unique posterior papillary muscle $(2,08 \%$ of all posterior muscular bodies) we found a particular form of the muscular body, and we called it "torch" or ",beacon”, that had the muscular body thinner in the lower half, its size increasing in width, reaching a maximumm width at its upper extremity, from where broke-loose four extra muscules that gave birth to beams of valvular cordages.

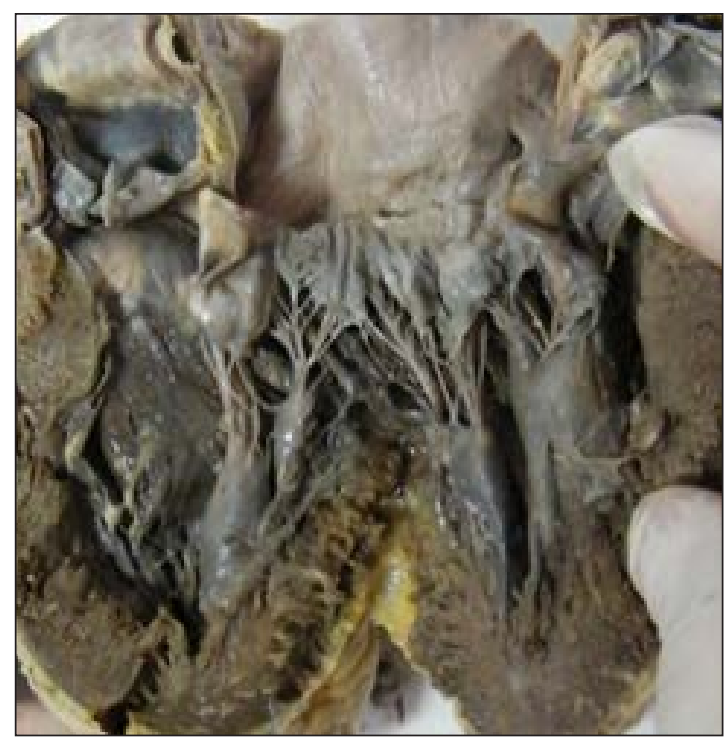

Figure. 4. A. left anterior papillary muscle with two parallel bodies, the right one bigger and conical and the other left, fusiform. B.left posterior papillary muscle formed by thAe muscular bodies, one righ (cylindrical, less volume), inner (cylindrical, thinner) and left (conical, shorter and thick)

Frequently, the base of the muscular bodies was punched, presenting one or two oval slots, thus implanting at the ventricular wall by two or three 
roots.

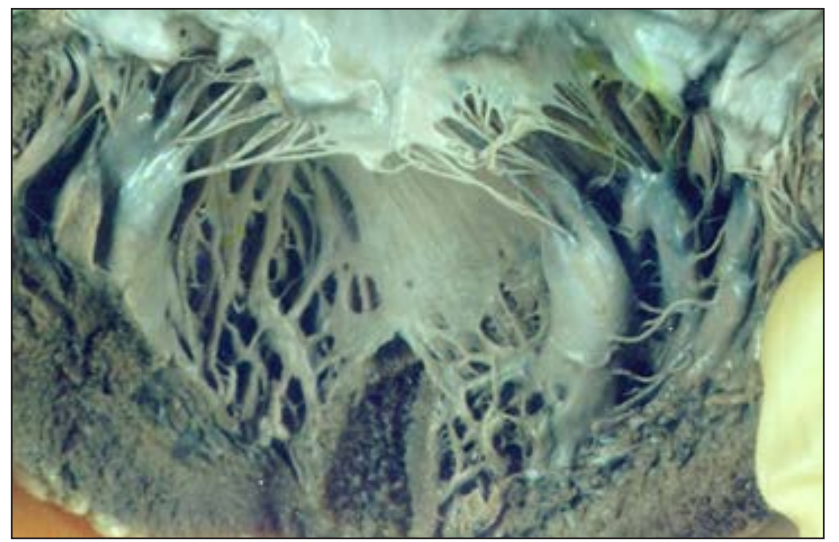

A

B

Figure 5. A. left anterior papillary with 3 muscular bodies, 2 anterior and conical and the third, posterior, being cylindrical (thicker). B. left posterior papillary muscle with 3 muscular cones: right (conical) thicker, inner (arcuated, situated on a posterior plan to others) and left cylindrical (thinnest).

At their valvular extremity, the muscular bodies give insertion to cordage tendons, wich can be drawn directly from their peak or from 2-4 small cones posed on upper extremity of the muscular bodies.

At different levels of the muscular body are detaching parietal cordage tendons (for the ventricular wall) or intermuscular cordage tendons between the muscular bodies of the same papillary muscule, or, more rarely, between the muscular bodies of the two papillary muscules of the left ventricle.

In case of the papillary muscule with two muscular bodies, those can be linked by a muscular bridge, transverse or oblique, carrying out various aspects.

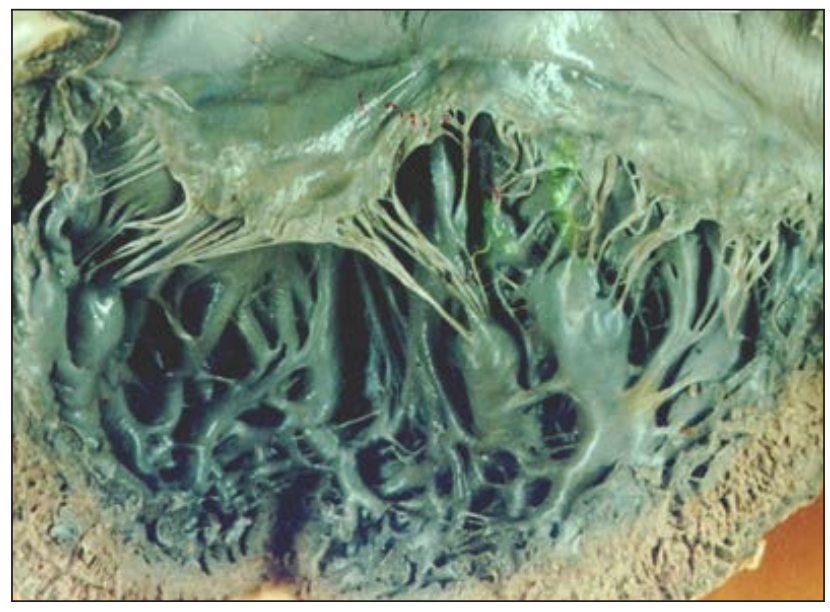

Figure 6. Double left papillary muscles. A. anterior with the reversed 'N'letter; $B$. the 'H'letter'.

Thus, in 6 cases $(10,71 \%$ of the 56 cases $)$, muscular bridges realized the letter „H” appearance, 4 casea being at the anterior papillary muscule $(18,75 \%$ of the anterior papillary muscule) and 2 cases at the posterior papillary $(16,67 \%$ of the posterior papillary muscules).

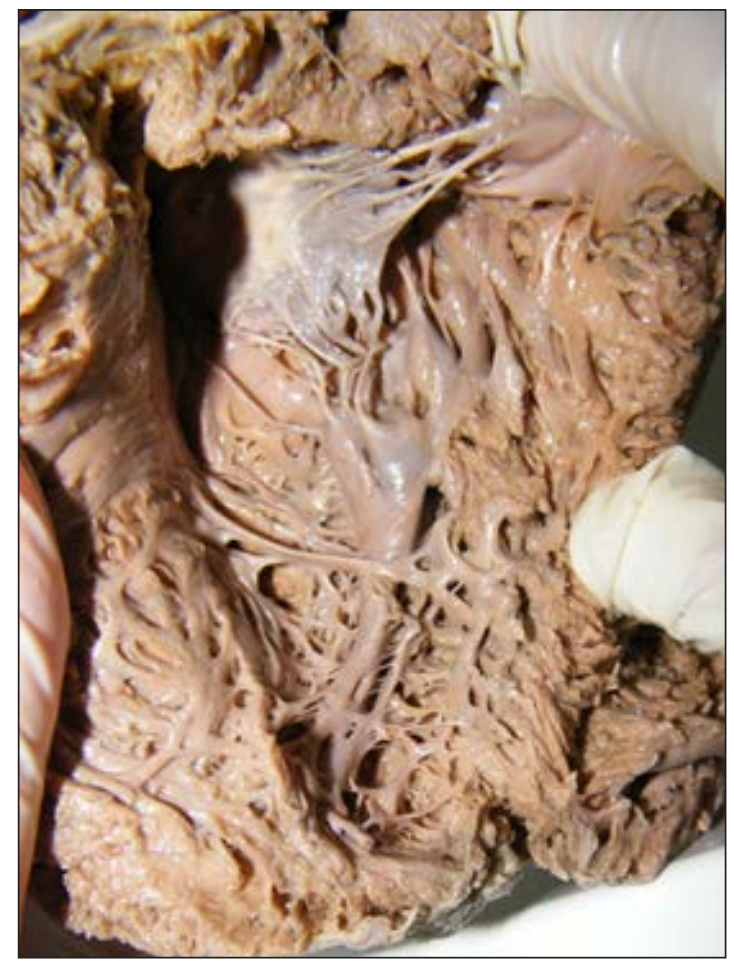

Figure 7. The posterior papillary in the 'torch'shape. 


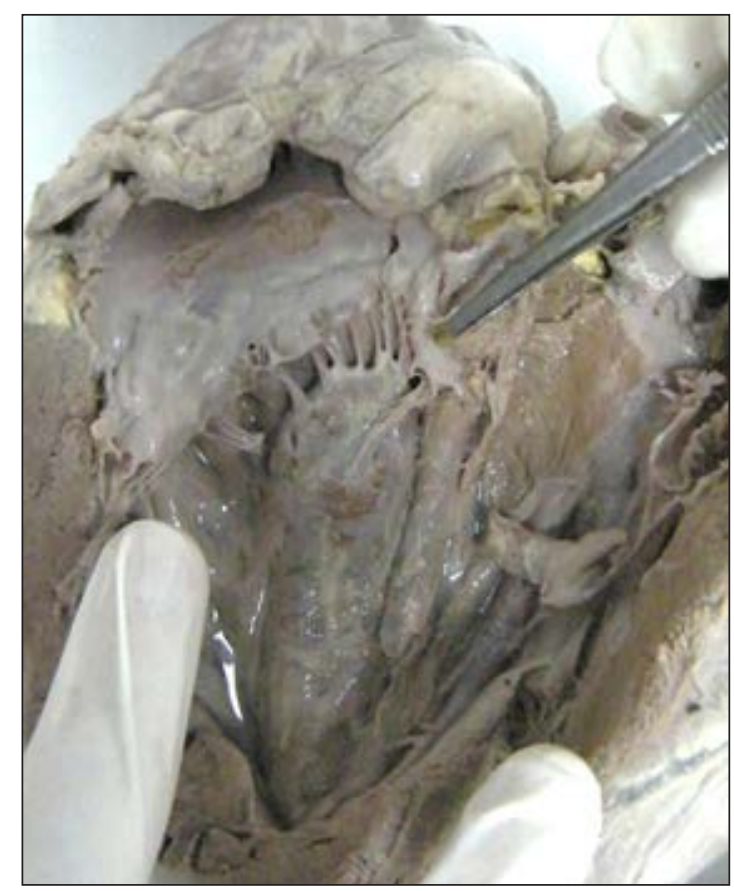

Figure 8 Posterior papillary muscle with 2 muscular bodies, cylindrical and unequal

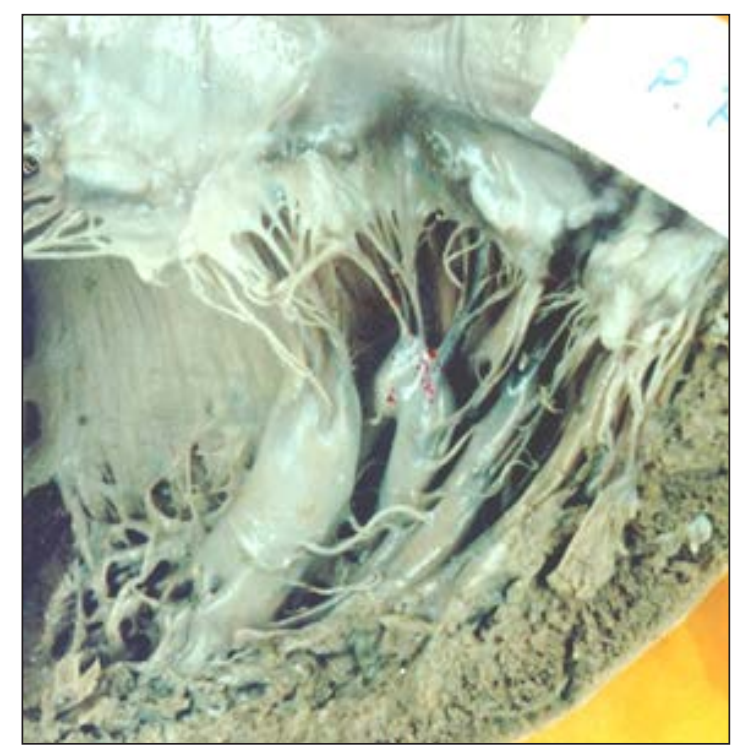

Figure 9. The left posterior papillary muscle with four parallel muscular bodies: right (conical) thicker ( perforated base), second (first in middle, arcuated, found on posterior plan then the other three), third ( second in middle, thinner, conical elongated), and left conical

In other 4 cases $(7,14 \%$ of 56 cases $)$, aspect encountered only to the anterior papillary muscule $(12,5 \%$ of anterior papillary) the presence of muscular bridges achieve the appearance of the "N" letter. Also in 4 cases the muscular bridges achieve tehe appearance of reversed „N" letter, 2 cases being at the anterior papillary muscule $(6,25 \%$ of anterior papillary muscules) and 2 cases at the posterior papillary muscules $(8,33 \%$ of posterior papilary)

\section{Discussions}

The name of anterior and posterior [18], shows that classical descriptions were made on oppend cords on the anterior face and upside down. If we turn the cord with the long axis inferior and oblique and to the left, we see that the anterior papillary muscule is actually antero-lateral, and the posterior papillary muscule is inferior and right (postero-septal or postero-medial).

Table I The number of the muscular bodies at the level of the two papillary muscles of the left ventricle

\begin{tabular}{|l|l|l|l|l|l|l|}
\hline author & unique & double & triple & $\begin{array}{l}4 \\
\text { bodies }\end{array}$ & $\begin{array}{l}5 \\
\text { bodies }\end{array}$ & $\begin{array}{l}6 \\
\text { bodies }\end{array}$ \\
\hline Gunnal & $46,55 \%$ & $43,11 \%$ & $31,90 \%$ & $21,55 \%$ & - & - \\
\hline Ozan & $43,3 \%$ & $30 \%$ & $26,7 \%$ & - & - & - \\
\hline Kavimani & - & - & - & $7 \%$ & $4 \%$ & $2 \%$ \\
\hline $\begin{array}{l}\text { Personel } \\
\text { cases }\end{array}$ & $28,57 \%$ & $57,14 \%$ & $10,71 \%$ & $3,57 \%$ & - & - \\
\hline
\end{tabular}

The number of the muscular bodies at the level of the two papillary muscules of the left ventricle.

It is noted that [19] does not find other papillary muscules but only with 3 muscular bodies, $[8,9]$ with 4 muscular bodies and only [9] finds at the left papillary muscule 5 and even 6 muscular bodies, and this in latter point only in oane case, to the posteromedial papillary muscule.

In case where each papillary muscule is represented by a single muscular body, our results are lower compared with the results of [8] with $17,98 \%$, compared to [19] lower by $14,73 \%$. 
We found frequent cases when one of the papillary muscule consists of two muscular bodies, and our statistic is higher by $14,03 \%$ compared to [8] and by $27,14 \%$ compared to [Ozan]. There are differences in case the papillary muscule presents three musular bodies, our results being lower by $15,99 \%$ compared to [19] and by $21,19 \%$ to [8]. We haven't found a papillary muscule consists more than 4 muscular bodies, this being present only on posteomedial papillary.

Hosapatna [15] finds that in the most cases in the left ventricle exists only two papillary muscules, cases when only one of the two left ventricle papillary muscules presents two bodies being redeuced. Spreeuwers [10] finds only 2-3 muscular bodies for a papillary, the cases with multiple muscular bodies are rare.

Table II. the number of the muscular bodies at the anterolateral papillary muscule of the left ventricle.

\begin{tabular}{|l|l|l|l|l|l|l|}
\hline author & unique & double & triple & $\begin{array}{l}4 \\
\text { bodies }\end{array}$ & $\begin{array}{l}5 \\
\text { bodies }\end{array}$ & $\begin{array}{l}6 \\
\text { bodies }\end{array}$ \\
\hline Solomon & $67 \%$ & $27 \%$ & $4 \%$ & $1 \%$ & $1 \%$ & - \\
\hline Kavimani & $62 \%$ & $31 \%$ & $2 \%$ & $2 \%$ & $2 \%$ & - \\
\hline Gunnal & $68 \%$ & $29 \%$ & $4 \%$ & - & - & - \\
\hline Roberts & $75 \%$ & - & - & - & - & - \\
\hline $\begin{array}{l}\text { Personal } \\
\text { cases }\end{array}$ & $31,25 \%$ & $56,25 \%$ & $12,50 \%$ & - & - & - \\
\hline
\end{tabular}

In case of the antero-lateral paillary muscule with single muscular body (unoque), we find that our results are much lower of those of the consulted literature, and that are differences between 30,75\% [9] and $43,75 \%$ [20], to $[13,8]$ differences being $35,75 \%$ and $36,75 \%$. We have encountered a high percentage in case of the papillary muscule with two muscular bodies, the differences being greater in our statistics by $29,25 \%$ [ 13 ] and by $25,25 \%$ to [9], compared with the results of [Gunnal] by $27,25 \%$. [15] finds a reduced number number of such cases. In those cases, the two muscular bodies can be joined by muscular bridges (strips) realizing various characteristic aspects. In four cases $(7,14 \%$ of all cords and 22,22\% of double antero-lateral papillary muscule) they presented "H” letter aspect, $[8,9]$ encountered this aspect in $2 \%$ of cases.

In four cases $(7,14 \%$ of all cords and $22,22 \%$ on double antero-lateral papillary muscule) the two muscule bodies with strip made the appearance of the „N" letter, and in two cases $(11,11 \%$ of double anterolateral papillary muscule) realized reversed „N" letter, issues that we have not found cited in consulted literature. In other cases, the two muscular bodies wereparallel and could present intermuscular cordage tendons between them. Gunnal and Kavimani $[8,9]$ cite cases with attained appearance of the "V" or ,Y" letter, wich we have not encountered in our study. In cases when the antero-lateral papillary consists 3 muscular bodies, the number of cases that we found is higher by $8,5 \%$ to $[13,8]$ and by $10,5 \%$ to [9]. In one of two cases, 2 muscular bodies (middle and left ) were connected by a muscular bridge, making the appearance of reversed „N" letter $(4,17 \%$ of cases of posterior papillary with 3 muscular bodies). We haven't found antero-lateral muscule with more than 3 muscular bodies, Solomon [13] encountered 4 cases $(1 \%$ of cases ) and with 5 muscular bodies $(1 \%$ of cases ). Kavimani [9] finds antero-lateral papillary formed by 4 and 5 muscular bodies in $2 \%$ of cases.

Table III The number of muscular bodies of posteromedial papillary muscules in left ventricle

\begin{tabular}{|l|l|l|l|l|l|l|}
\hline author & unique & double & triple & $\begin{array}{l}4 \\
\text { bodies }\end{array}$ & $\begin{array}{l}5 \\
\text { bodies }\end{array}$ & $\begin{array}{l}6 \\
\text { bodies }\end{array}$ \\
\hline Solomon & $50 \%$ & $36 \%$ & $11 \%$ & $3 \%$ & - & - \\
\hline Kavimani & $49 \%$ & $42 \%$ & $4 \%$ & $2 \%$ & $2 \%$ & $2 \%$ \\
\hline Gunnal & $49 \%$ & $29 \%$ & - & - & - & - \\
\hline Roberts & $75 \%$ & - & - & - & - & - \\
\hline $\begin{array}{l}\text { Personal } \\
\text { cases }\end{array}$ & $25 \%$ & $58,33 \%$ & $8,33 \%$ & $8,33 \%$ & - & - \\
\hline
\end{tabular}

In cases wich postero-medial papillary muscule consists only one muscular body, the results we found are lower than those we find in the consulted literature by $24 \%$ to $[5,8]$, by $25 \%$ to [13] and by $50 \%$ to [20]. In most of one cases postero-medial papillary muscle was composed of three muscular bodies, personal percentages being higher by $29,33 \%$ to [ 8 ], by $22,33 \%$ to [13] and by $16,33 \%$ to [9]

As with the anterolateral papillary muscle, the parallel muscle bodies can be interconnected with eachother by muscular bridges (strips), realizing the form of capital letters. The form of the „H” letter we encounntered in 2 cases $(8,33 \%$ of posteromedial 
papillary muscules) aspect that $[8,9]$ find in $2 \%$ of cases, the reversed „N" letter form we found in 2 cases, aspect that we didn't found in the consulted literature. Also to this papillary muscule are cited forms of ,V” and „Y" letters without being specified percentages.

Posteromedial papillary muscule formed by 3 muscular bodies we found in a higher percentage by $4,33 \%$ to Kaimani and lower by $2,67 \%$ to[ Solomon]. Our results in case of the papillary muscules formed by 4 muscular bodies are higher by $5,33 \%$ to [13] and by $6,33 \%$ to [9]. We did not find posteromedial papillary muscules consisting more than 4 muscular bodies.

Only Kavimani [9] describes cases with 5 or 6 muscular bodies, each variant by $2 \%$ of cases.

The shape of the muscular bodies of the pappilary muscles varries and described differently in by the special literatture. So,the conical shape that we found most frequently ( $63,21 \%$ of cases), is mentioned by [8] in a smaller percentage by $12,21 \%$ at the anterolateral papillary muscule and by $25,90 \%$ to [9], and at the posteromedial papillary higher by $50,83 \%$ to [9]. Arcuated shape of the muscular body, found in $9,43 \%$ of cases is more frequent by $5,43 \%$ than [8], that finds this only at the posteromedial papillary, but we find it in both papillary muscules of the left ventricle, in our statistcs beeing more frequently by $8,25 \%$ to [8]. Cilindrical shape of the muscular body, found in $18,87 \%$ of cases, we associated with the shape of the flat end muscular body, described by $[8$, 9]. We found it beeing more frequently only by $0,87 \%$ to [8] and by $7,87 \%$ to [9].

For [15] the muscular bodies of the papillary muscules in the left ventricle are always conical.

\section{Conclusions}

This study is useffull for the anatomists, cardiologists and cardiac surgeonts. The normal function of the mitral valve depends on anatomical and mecanical integrity of the papillary muscules.
Cardiac surgerry needs to improve the knoledge of precise anatomy of papillary muscules, choardae tendineae and the mitral valve, of the anatomical variant of those, asspects that have an considerable impportance because of the role they have in the surgical treatement of the mitral valve prolapse and replacement of it [9]. After [9] the reconstruction of the subvalvular mechanism in the left ventricle, needs a very good knoledge of the morfology of the papillary muscules, with an special importance in describing the clinical sindroms of the dissfunction of the papillary muscules, hypertrophic papillary muscules, atrophy of papillary muscules, disruption of papillary, all these increasing the clinical semnification of the papillary muscules. After [11, 21, $22]$ the posteromedial papillary muscule, probably because of the lower blood suplly, it breaks frequently then the anterolateral papillary.

The shape of the papillary muscules influences the blood circulation, the chances of the obstruction in left ventricle beeing higher in the fan shape papillary hypertrophia (aspect that we didn't find) and to wide appex papillary. The papillary muscule, that facilitates the cardiovascular physiology is the conical shape one, inserted on the ventricular wall, that leaves empty the center of the cavity [8].

Solomon [13] that studied the variations of the papillary of the mitral valve on 100 cases, states that the mitral mechanism, including the papillary muscules, is unique for each subject such as own mark.

\section{References}

1. Testut, L. (1921). Cœur. In: Traité d'anatomie humaine. Angéiologie, Livre IV, Ed. Gaston Doin: Paris, 3-59.

2. ******** (1998). Terminologia Anatomica. International Anatomical Terminology. Federativ Committee on Anatomical Terminology. Ed. Thieme-Stuttgart, 75-77

3. Rouvière, H. \& Delmas, A. (1997). Anatomie 
du cœur. In: Anatomie humaine. descriptive, topographique et fonctionnelle. Tome 2. Tronc. Ed. Masson: Paris, 125-157.

4. Bouchet, A. \& Cuilleret, J. (1991). Anatomie topographique, descriptive et fonctionnelle. $2 \mathrm{Le}$ Cou, Le Thorax. Ed. Simep: Paris, 985-993.

5. Kamina, P. (2007). Cœur et péricarde. In: Anatomie Clinique. Tome 3. Thorax. Abdomen. Ed. Maloine, Paris, 95-125.

6. Christides, C. \& Cabrol, C. (1994). Anatomie du cour et du pericarde. In: Chevrel J.P.: Le Tronc; Anatomie Clinique. Ed. Springer-Verlag, Paris, 141-172.

7. Moore, K. \& Dalley, A. (2001). Anatomie médicale. Aspects fondamentaux et applications cliniques. Ed. De Boeck Université, Bruxelles, 127-131.

8. Gunnal, S.A., Wabale, R.N. \& Farooqui, M.S. (2013). Morphological variations of papillary muscles in the mitral valve complex in human cadaveric hearts. Sing.Med.J. 54(1), 44-48.

9. Kavimani, M., Johnson, W.M.S. \& Jebakani, C.F. (2011). Morphology of mitral papillary muscles -the bridges of vital link across the heart muscles. National J.Basic Med.Sciences (NJBMS). 2(1), 18-22.

10. Spreeuwers, L.J., Bangma, S.J., Meerwaldt, R.J.H.W., Vonken, E.J. \& Breeuwer, M. (1966). Detection of trabeculae and papillary muscles in cardiac mr images. Am. Heart J. 71(3), 356-362.

11. Fradley, G.M. \& Picard, H.M. (2011). Rupture of the posteromedial papillary muscle leading to partial flail of the anterior mitral leaflet. Circulation. 123, 1044-1045.

12. Tempe, D.K., Datt, V., Banerjee, A. \& Gandhi, A. (2007). Choardae tendineae from posteromedial papillary muscle inserting into the anterior mitral leaflet - an unusual presentation. Ann. Card. Anaesth.10, 63-67.

13. Solomon, V. \& Nayak, M.V. (1995). Variations in the papillary muscles of the normal mitral valve and their surgical relevance. J.Card.Surg. 10(5), 597-607.

14. Filipoiu, FL.M. (2012). Cordul. Anatomie, repere embriologice și noţiuni de infrastructură a miocardului. Ed. Prior, București, 148-150; 167-169.
15. Hosapatna, M., Souza, D.A., Das, A., Padmashali S., Ankolekar V. \& Souza D.A.S. (1995). Morphology of papillary muscles in human adults: a cadaveric study. J. Heart Valve Dis. 4 (Suppl 2),115-123.

16. Silver, M.D., Lam, J.H.C., Ranganathan, N. \&Wigle, E.D. (1971). Morphology of the human tricuspid valve. Circulation, 43, 333-348.

17. Berdajs, D., Lajos, P., Turina, I.M. (2005). A new classification of the mitral papillary muscle. Med. Sci. Monit. 11(1), BR18-21.

18. Anderson, H.R., Razavi, R. \& Taylor, M.A. (2004). Cardiac anatomy revisited. J.of Anat. 205(3), 159-177.

19. Ozan H., Kocabiyik, N., Demirel, B., Yalçin, B., Cömert, A. (2012). Pattern of connection between papillary muscle and chordae tendineae of left ventricle. Gulhane Med J. 54(4): 275-278

20. Roberts C.W. \& Cohen S.L. (1972). Left ventricular papillary muscles description of the normal and a survey of conditions causing them to be abnormal. Circulation. 46(1):138-154

21. Andersen, J. A. \& Fischer-Hansen, B. (1973). Isolated acute myocardial infarction of papillary muscles of the heart. Clinicopathological study of 9 cases. Br Heart J. 35(8): 781-786.

22. Czarnecki, A., Thakrar, A., Fang, T., Lytwyn, M., Ahmadie, R., Pascoe, E. \& Jassal, S.D. (2008). Acute severe mitral regurgitation: consideration of papillary muscle architecture. Cardiovascular Ultrasound. 6:5-8. 